\title{
(META)PRAGMÁTICA DA VIOLÊNCIA LINGUÍSTICA: PATOLOGIZAÇÃO DAS VIDAS TRANS EM COMENTÁRIOS ONLINE
}

\author{
(META)PRAGMATICS OF LINGUISTIC VIOLENCE: \\ PATHOLOGIZATION OF TRANS LIVES IN \\ COMMENTS ONLINE
}

\section{Danillo da Conceição Pereira Silva*}

\section{RESUMO}

Este artigo tem como objetivo construir inteligibilidades contingentes acerca de eventos interacionais marcados pela violência linguística praticada contra pessoas trans, a partir da análise de atos de fala em circulação em comentários online. Nesse sentido, discuto os resultados de uma pesquisa qualitativa, inspirada na etnografia virtual, feita entre julho de 2015 e julho de 2016, na seção de comentários do site de notícias brasileiro G1, em três matérias jornalísticas relacionadas à encenação de uma crucificação realizada pela atriz e modelo transexual Viviany Beleboni, durante a $19^{\mathrm{a}}$ edição da Parada do Orgulho LGBT de São Paulo. Do ponto de vista teórico, são mobilizados saberes relativos à noção de linguagem como performance, às discussões sobre a violência linguística e ao processo de patologização das vidas trans. No trabalho analítico empreendido, foram focalizados os processos de entextualização acionados pelos participantes em seus comentários online. Assim, em razão do olhar adotado sobre os dados gerados, o que se observa é a produção de uma (meta) pragmática engajada no reestabelecimento de contextos violentos, relativos a discursos médico-científicos patologizantes, com vistas a dotar de força ilocucionária os atos de fala transfóbicos, capazes de subalternizar e ferir pessoas trans por meio da linguagem. Desse modo, a pesquisa realizada permitiu salientar o potencial de um modelo indisciplinar e descentrado de investigação em linguagem, comprometido com a compreensão de práticas semióticas situadas na elaboração da realidade social, particularmente em tempos de alta reflexividade e trânsitos textuais intensos.

Palavras-chave: pragmática; violência linguística; transfobia; entextualização; estudos queer.

\section{ABSTRACT}

This article aims to construct contingent intelligibilities about interactive events marked by linguistic violence practiced against trans people, from the pragmatic (meta) analysis of speech acts in circulation in online commentaries. In this sense, the results of a qualitative, ethnographic-inspired research conducted by the author between July 2015 and July 2016 are presented and discussed in the comments section of the Brazilian news site G1, in three journalistic articles related to the staging of a crucifixion performed by actress and

\footnotetext{
* Instituto Federal de Educação, Ciência e Tecnologia de Alagoas (IFAL), Santana do Ipanema, AL, Brasil. danillosh@gmail.com, https://orcid.org/0000-0002-5879-5999
} 
transsexual model Viviany Beleboni during the 19th edition of the LGBT Pride Parade in São Paulo. From the theoretical point of view, knowledge about the notion of language as performance, discussions about linguistic violence and the process of pathologization of trans lives are mobilized. In the analytical work undertaken, we focused on the interpretation of linguistic contextualization clues, indexicality dynamics and the processes of entextualization triggered by the participants in their online commentaries. Thus, due to the adopted view of the data generated, what is observed is the production of a pragmatic (meta) pragmatics engaged in the reestablishment of violent contexts, related to pathological medical-scientific discourses, with a view to providing illocutionary force with the acts of speaks transphobic, capable of subalternizing and hurting trans people through language. In this way, our research allowed us to highlight the potential of an undisciplined and decentralized model of language research, committed to the understanding of semiotic practices in the elaboration of social reality, particularly in times of high reflexivity and intense textual transits.

Keywords: pragmatic; linguistic violence; transphobia; entextualization; queer studies.

\section{INTRODUÇÃO}

Como resultado da Revolta de Stonewall, em 28 de junho de 1969, nos Estados Unidos da América, e da posterior emergência das Paradas do Orgulho Gay nos anos seguintes, uma gama de debates e mobilizações sociais levou à retirada da palavra "homossexualismo" do Manual Diagnóstico e Estatístico de Transtornos Mentais, o DSM, editado pela Associação Americana de Psicologia (APA, sigla em inglês), em 1973, e da Classificação Internacional de Doenças vigente à época, o CID-10, publicado em 1990 pela Organização Mundial da Saúde, a OMS. Assim, podemos dizer, grosso modo, que essa foi a trajetória que culminou na despatologização da homossexualidade, ao menos em termos de marcos institucionais.

À revelia disso, o "transexualismo" e o "travestismo" continuaram referenciados no CID-10 como modalidades de "transtornos mentais", classificados como "transtornos de identidade de gênero". Atualmente, desde a divulgação do CID-11, em junho de 2018, a OMS decidiu pela retirada das transexualidades desse grupo de patologias psiquiátricas para reenquadrá-las na seção de "condições relacionadas à saúde sexual", sendo agora classificadas como "incongruência de gênero". ${ }^{1}$ É curioso perceber que a retórica que justificou a inclusão da

1. Se, por um lado, tal mudança foi comemorada como a despatologização das transexualidades por muitos segmentos sociais, inclusive alguns deles ligados aos ativismos LGBT, aos feminismos trans e aos estudos de gênero na academia, afinal foi uma decisão histórica, em 28 anos, por outro lado, outros grupos, aos quais me afino, veem nessa mudança mais uma ação do Estado no sentido de oferecer à população trans uma cidadania precarizada, parcial, ou, ainda, de barganhar com essa conquista de direitos e reconhecimento (ainda que parciais e frágeis) em troca de continuarem a ter sua autonomia tutelada, legitimada apenas mediante a captura dessas vidas por outros dispositivos 
homossexualidade no CID-9 era exatamente a mesma utilizada tacitamente pelos "cientistas da mente" - psiquiatras, psicólogos e psicanalistas - a fim de justificar a manutenção das referências nosológicas às experiências trans. Tais argumentos médico-científicos circulavam basicamente em torno da elaboração de uma imagem universal das pessoas trans enquanto adoecidas, depressivas, com dificuldades importantes de aprendizagem, memorização, socialização e com uma vida sexual fora de padrões saudáveis, desregulada, diriam.

Tal posicionamento escamoteia que a possível ocorrência desses fatores é fruto das dinâmicas de violência e exclusão, próprias do dispositivo da transfobia, a que essas pessoas estão submetidas diariamente, desde aquelas experimentadas na família até as violências que acabam expurgando-as dos espaços formais de escolarização, dos serviços de saúde, do acesso ao espaço público, cerceando, inclusive, suas possibilidades de acessar o mercado de trabalho formal, restando, para muitas/os, o tão estigmatizado trabalho sexual como única opção laboral. Isto sem falar, é claro, de outras políticas de morte (MBEMBE, 2018) trans, corporais e simbólicas, em funcionamento no Brasil, o qual vem sendo considerado, anos a fio, como o país que mais mata pessoas trans no mundo, conforme aponta relatório da TransGender Europe ${ }^{2}$.

A mesma sociedade que produz o adoecimento (quando não a morte) das pessoas trans elabora para estas um discurso de patologização das suas performances identitárias, tomadas em si mesmas como adoecidas face à sua inconformidade com o modelo supostamente natural homem/mulher. Disso decorre a retirada de sua autonomia sobre suas vidas, uma vez que "doentes de gênero" passam a ter suas existências tuteladas através de uma série de dispositivos engajados nessa tarefa. Boa parte dos investimentos de poder sobre as vidas trans está pautada em discursos médico-científicos (aqueles relativos às narrativas da biologia, da saúde, da psiquiatria, da psicologia, da psicanálise e afins).

Nesse sentido, partindo de uma postura epistemológica e política que toma a linguagem como performance (AUSTIN, [1962] 1990; BUTLER, 1997; 2017a; DERRIDA, 1991a; 1991b), ou seja, como forma de ação de sujeitos situados sobre o real, produzindo-o por meio de atos de linguagem, é possível compreender

e suas técnicas discursivas. Para uma discussão mais detida sobre essa trajetória de apropriação das vidas trans pelo saber médico, ler Leite e Santos (2016).

2. A TransGender Europe - TGEU é uma Organização Não-Governamental (ONG) engajada na promoção internacional da cidadania trans integral e que anualmente conduz a pesquisa Transrespect versus Transphobia Worldwide (TvT), a qual mapeia a violência exercida contra essa parcela da população em diversos países. 
como práticas semióticas de diferentes ordens estão implicadas na elaboração da transfobia, inclusive naquela faceta relativa à patologização de experiências trans.

Assim, considerando os efeitos do momento atual da globalização, especialmente aqueles concernentes à ampliação das possibilidades tecnológicas de interconexão em rede, as dinâmicas de fluxo e trânsito de signos em espaços digitais compartilhados tanto ampliaram as possibilidades de projeção de performances identitárias em espaços públicos, quanto potencializaram as condições de reflexividade dos sujeitos sobre a elaboração (contínua) dessas identidades contingentes.

Como consequência desses processos característicos da modernidade recente (RAMPTON, 2006) ou da modernidade tardia (GIDDENS, 1991; 2002), instauram-se nesses espaços interacionais acirradas disputas entre diferentes narrativas sobre a vida social, as quais visam a obter relativa hegemonia sobre direções interpretativas sinalizadas (SILVA, 2019), marcadas na luta pelo domínio dos processos de contextualização (FABRÍCIO, 2014) em interações discursivas em curso.

Desse modo, neste artigo, apresento e rediscuto os resultados de uma pesquisa (SILVA, 2017) qualitativa de inspiração etnográfica virtual (HINE, 2002), realizada entre julho de 2015 e julho de 2016, na seção de comentários do mais acessado site de notícias brasileiro, o $G_{1}$, em três matérias jornalísticas relacionadas à encenação da atriz e modelo transexual Viviany Beleboni, durante a $19^{\mathrm{a}}$ edição da Parada do Orgulbo LGBT de São Paulo. Neste trabalho, meu objetivo consiste em produzir inteligibilidade acerca da produção de atos de fala presentes em comentários online engajados na produção da violência linguística (SILVA; ALENCAR, 2013; 2014) contra pessoas trans, especificamente no que tange às pistas linguísticas de contextualização acionadas (GUMPERZ, [1982] 1998), às dinâmicas de indexicalidade (SILVERSTEIN, 2003) e à entextualização (BAUMAN, BRIGGS, 1990) de discursos médico-científicos patologizantes nos atos de fala proferidos com vistas a exercer a transfobia.

Inspirado pelo anseio de uma prática de pesquisa em linguística aplicada radicalmente INdisciplinar (MOITA LOPES, 2006; FABRÍCIO, 2017), acredito que focalizar a (meta)pragmática da violência linguística de motivação transfóbica age no sentido de desnaturalizar saberes-poderes médico-científicos e seus efeitos de verdade sobre crenças biologicistas da relação entre corpo e identidade, incrustradas na episteme modernista e colonial. Assim, o investimento teóricometodológico deste trabalho significa sobre a necessidade antiga, e crescente, de um horizonte para os estudos da linguagem que, em aliança com corpos precarizados e 
na escuta de vozes abjetas, participe de um movimento de "insurreição de saberes subjugados" (FOUCAULT, 1980, p. 81).

\section{UMA VISADA QUEER SOBRE AS NORMAS DE GÊNERO E SUAS TÁTICAS: DA DISSIDÊNCIA À PATOLOGIZAÇÃO}

A conexão teórica que abre a possibilidade de investigação do funcionamento (meta)pragmático dos atos de fala violentos, "motivados" pela performance de gênero de suas vítimas, está centrada na visada performativa da linguagem, como proposta por Austin ([1962] 1990) e Rajagopalan (2010), revisada por perspectivas como as de Derrida (1991a, 1991b) e Butler (1997). A exemplo do demonstrado por Pinto (2007), é tal premissa austiniana a chave-mestra que abre um caminho teórico singular para pensarmos questões demasiado caras às Humanidades, como a noção de identidade, distanciando-nos de um prisma internalista e representacionalista, signo sob o qual esteve boa parte da história das ideias filosóficas e linguísticas sobre esse tema e sobre tantos outros.

Pensar que a identidade não é um dado interno ao "sujeito", mas um efeito instável e continuamente em vias de implementação nas infindáveis performances (ações) que realizamos, nos mais diversos contextos, sobretudo por meio da linguagem, dos discursos, inverte a dinâmica de compreensão da questão identitária e subjetiva. Não há identidade anterior ao uso de signos, assim como não há sujeito anterior à linguagem, ao discurso. É na ação que ambas as instâncias se constituem e produzem, inclusive, os efeitos de estabilidade que geram a ilusão de univocidade, delimitação estanque, estabilidade e naturalidade de que possam gozar.

Em razão dessa orientação, seria um truísmo latente sublinhar o papel que a história e a cultura, ou melhor, que as narrativas históricas e culturais que permeiam as trajetórias de vida dos sujeitos, exercem na constituição das performances identitárias nas práticas de linguagem. $\mathrm{Na}$ medida em que estes são interpelados e atravessados por diferentes discursos, instituições e posições, configuram-se delineadas suas possibilidades de agência nos diversos enquadres interacionais dos quais possam participar. Desse modo, as identidades situadamente produzidas passam a ser compreendidas como resultantes, dentre outras coisas, dos múltiplos determinantes sociais de uma época localizável em termos espaciais e temporais e não um pré-construído plenamente autônomo e já dado, supostamente prévio à interação, à sociedade, à história, à sua performance.

Tendo em vista a crescente complexidade da vida social na modernidade recente, seu alto potencial de reflexividade e o trânsito multidimensional de signos, 
discursos e práticas que lhe são característicos, bem como as inúmeras semioses nas quais a vida humana se dá, tornam-se também múltiplos os contextos de ação nos quais as subjetividades se produzem e as "identidades" são performatizadas. Dentre esses universos complexos de agência, socioculturalmente situados na história, está aquele relativo às experiências de gênero. Ou seja, na perspectiva assumida neste trabalho, "o gênero não deve ser interpretado como uma identidade estável ou um lugar em que se assenta a capacidade de ação e de onde resultam diversos atos", mas, ao contrário disso, enquanto "uma identidade fragilmente constituída no tempo, instituída em um espaço exterior mediante uma reiteração estilizada de atos (BUTLER, [1990] 2017a, p. 235).

Desse modo, tendo em vista o caráter temporal da produção de performances de gênero enquanto atos insaturavelmente reiterados, a cisgeneridade pode ser pensada enquanto um construto relativo às "compreensões socioculturais ocidentais e ocidentalizadas de gênero tidas como naturais, normais e biológicas, que são por sua vez as compreensões que fundamentam as leituras sobre vivências e corpos em termos de gênero" (VERGUEIRO, 2015, p. 61). Nesse sentido, a "cisnormatividade", ou seja, a elevação da cisgeneridade à categoria de norma, funciona como instrumental analítico e político transfeminista afeto à crítica da validação dos modelos corporais e de gênero social de pessoas não transexuais (calcadas em binarismos dicotômicos, a exemplo do par homem/mulher) como norma universal e compulsória de existência, exercendo, por isso, violência disciplinarizante e exclusão contra pessoas transexuais, travestis, transgêneras e gênero diversas, a exemplo da transfobia.

Nesse sentido, como produto do apagamento dos complexos imbricamentos de saberes-poderes travados no interior dos diversos discursos que disputam a legitimidade nas narrativas sobre o gênero (por exemplo, os da religião e os da saúde), determinadas "estilizações" ganham efeitos de estabilidade, tornando-se parâmetro regulatório para a determinação de quais formas de vida são válidas, possíveis e vivíveis. Em tal perspectiva de hierarquização da vida está implicada a produção de uma ética segundo a qual se estabelece, por sua vez, quais vidas são dignas de serem protegidas, inclusive mediante a relativização de prerrogativas constitucionais e de direitos humanos, e quais são choráveis ou dignas de luto (BUTLER, 2017b) em face da violência.

No interior dessa lógica discursiva, muitos significados violentos são gestados e é deles que emergem atos de fala capazes de ferir aquelas pessoas que fazem uma experiência de corpo/de gênero/de sexualidade que não seja inteligível a partir de um parâmetro cisheteronormativo, centrado na imaginada coerência inescapável 
entre sexo, gênero e desejo (BUTLER, 2017a). No influxo desses significados que exercem a transfobia, ou seja, que posicionam pessoas trans numa região subalterna da existência humana, endereçando-lhes um sem-número de violências, estão aqueles discursos que se valem da autoridade tácita de argumentações de natureza médica, as quais são tomadas como verdades inquestionáveis, transparentes, nãoideológicas, por serem, nesses termos, "científicas".

Tais discursos médico-científicos estão pautados na certeza de que "masculinidade e feminilidade são prerrogativas dos cromossomos e dos hormônios" (BENTO, 2014, p. 52), resultando disso a responsabilidade que as ciências médicas teriam no sentido de analisar, descrever, classificar e tratar sujeitos que padecessem de algum tipo de "transtorno" (leia-se, doença) no que tange a uma correta vivência do gênero. Como argumentam Bento e Pelúcio (2012), tal perspectiva patologizante dos corpos, identidades e desejos das pessoas trans, os quais passam a ser tutelados por instituições médicas e de estado graças aos efeitos de verdade gerados pelos saberes-poderes médico-científicos, deslegitimam a leitura de que a dicotomia natureza (corpo) versus cultura (gênero) não possui apoio fora da égide do pensamento cartesiano, uma vez que não existem condições simbólicas para se atribuir sentido ao corpo (ou qualquer uma de suas estruturas anatomofisiológicas) fora da cultura, ou seja, fora de marcos discursivos, sociais e políticos situados.

Desse ponto de vista, os corpos sexuados dentro do binarismo homem/ mulher, como representado nas literaturas médicas e suas narrativas, encontram nas existências trans os limites discursivos da sua lógica de inteligibilidade, de validade em face da norma, "uma vez que aqui o gênero significará o corpo, revertendo assim um dos pilares de sustentação das normas de gênero" (BENTO, 2014, p. 52). Abrese, então, espaço para outras possibilidades identitárias em termos de gênero, como consequência da problematização da lógica determinista na relação corpo-gênero. É dessa proliferação identitária que têm medo regimes de pensamento e políticas de natureza transfóbica e patologizante, pois uma vez questionadas as fronteiras impostas às vivências, tidas como determinações naturais, ganha saliência o caráter artificial, não-essencial, da matriz imposta como critério diagnóstico, desvelandose irreversivelmente a contingência radical tanto dos objetos desse saber médico (os corpos, os gêneros, as práticas sexuais), quanto do "olhar de quem analisa os deslocamentos enquanto sintomas de identidades pervertidas, transtornadas, disfóricas" (BENTO, 2014, p. 56).

É mediante a projeção (meta)pragmática dos significados em funcionamento no discurso transfóbico, em sua faceta patologizante, que a violência linguística é produzida, graças ao caráter performativo da linguagem. Na seção seguinte, buscarei 
produzir algumas incursões teóricas em torno desse paradigma epistemológico e político nos estudos da linguagem.

\section{SOBRE COISAS QUE FAZEMOS COM A LINGUAGEM: PERFORMATIVIDADE E VIOLÊNCIA}

Ao abandonar o recurso retórico calcado no par opositivo performativo/ constativo para explicar o funcionamento da linguagem ordinária, no curso de suas palestras em 1950, na Universidade de Harvard, John Langshaw Austin produziu uma ruptura significativa e altamente produtiva na tradição da filosofia analítica vigente à época no ocidente. A saber, mediante o argumento da "falácia descritiva" (AUSTIN, [1962] 1990, p. 23), empurrou a compreensão da linguagem utilizada na vida social de um marco lógico-positivista, centrado na noção de verdade/ falsidade em função de sua fidelidade na descrição da realidade, por isso de cariz essencialista e representacionalista, para bases antecipadamente pós-estruturalistas, desnaturalizantes e desconstrucionistas (OTTONI, 2002), a exemplo do que discuti na abertura da seção anterior.

Dito de outro modo, ao sustentar que todos os proferimentos, independentemente de suas características gramaticais, mais do que constatações ou descrições de realidades dadas previamente no mundo, seriam formas de ação atos de fala - dotadas da potencialidade de produzi-las, simultaneamente ao serem enunciadas, mediante o atendimento de condições "rituais" específicas para tal, estavam fundadas as bases para desdobramentos teóricos com alto potencial de crítica social. Tal fato se deve, especialmente, por tais perspectivas considerarem o calibre das possibilidades de intervenção humana, via linguagem, na produção das condições simbólicas e materiais de existência, estabelecendo uma relação de implicação incontornável entre linguagem e sociedade, construto epistemológico hoje tão caro e basilar à pragmática, ao campo aplicado dos estudos da linguagem, aos estudos de gênero e a tantas outras searas do conhecimento influenciadas pelas leituras de Austin e de seus leitores (SILVA; VERAS, 2016).

À revelia das operações formalizantes realizadas por John Searle no pensamento austiniano (RAJAGOPALAN, 1996, 2010; ALENCAR, 2005), amplamente incorporadas nas teorizações e nos modelos analíticos na Linguística, a obra de Austin em torno da questão dos performativos encontrou ressonância no pensamento filosófico de diferentes intelectuais. Um exemplo disso foram as reflexões desconstrucionistas propostas pelo filósofo Jacques Derrida sobre o trabalho de Austin. Dos alargamentos teóricos realizados por ele em Signature, event, 
context (1991) derivam contribuições fundamentais para a compreensão da natureza performativa da linguagem e, consequentemente, da produção e circulação translocal (BLOMMAERT, 2005; 2010) de significados que patologizam as vivências trans, mediante o exercício da violência linguística de natureza transfóbica em comentários online.

Dentre as incursões propostas pelo filósofo francês sobre o funcionamento da linguagem performativa, saliento aqui as características por ele atribuídas como intrínsecas a todos os signos ( $\mathrm{e}$, consequentemente, a todas as práticas comunicativas), nomeadas como citacionalidade e iterabilidade. Tais características dizem respeito à possibilidade constitutiva de eles serem, por um lado, extraídos de seus contextos primeiros, de sofrerem uma "iteração na ausência e além da presença do sujeito determinado e que empiricamente o emitiu ou produziu num contexto dado" (DERRIDA, 1991a, p. 21-22), e, por outro, citados, repetidos, enxertados em outros contextos.

Aprofundando essa reflexão, Derrida (1991b) afirma que a iterabilidade é a possibilidade de o signo ser repetido e alterado - o iter e o itera, do sânscrito, o novo e o repetido - mesmo na ausência de seu referente, comportando a mudança e o deslocamento no ato da repetição, ou seja, assinalando a impossibilidade de uma repetição mimética, sejam eles textos ou discursos. Já a citacionalidade, complementar à iterabilidade, diz respeito à repetição (iteração) citada em - deslocada para-outros lugares, produzindo diferenças graças aos efeitos de sua ruptura com contextos dados e de seus trânsitos por novos contextos, numa dinâmica que pode "engendrar infinitamente novos contextos, de forma absolutamente não saturável" (DERRIDA, 1991b, p. 25). É graças à possibilidade de iteração dos signos que estes podem ser reconhecidos/inteligíveis como fórmulas rituais que direcionam tipos específicos de ação, produzindo assim efeitos de aparente estabilidade via repetição. Assim, é possível dizer que "os enunciados são performativos porque resgatam outros enunciados iteráveis, ou seja, enunciados que se conformam às regras de uso, sendo transportados e atualizados nos contextos de interação" (GUIMARÃES; MOITA LOPES, 2016, grifo dos autores).

Também na esteira do diálogo crítico com o pensamento austiniano, Butler (2000), avaliando as consequências desses quase conceitos ${ }^{3}$ derridianos sobre os performativos, afirma que "[...] a performatividade deve ser compreendida não como um 'ato' singular ou deliberado, mas, ao invés disso, como a prática reiterativa

3. Para Derrida, o quase conceito seria a impossibilidade de o pensamento se organizar a partir de conceitos fixos, homogêneos e universais, desconstruindo assim parte da lógica do pensamento metafísico - pensamento binário, polarizado e hierarquizado. 
e citacional pela qual o discurso produz os efeitos que ele nomeia" (BUTLER, 2000, p. 111). Nesse sentido, a autora encontra na própria argumentação de Austin em torno da caracterização do performativo como "convencional", "ritual", "cerimonial" (AUSTIN, [1962] 1990) a brecha para reafirmar a posição defendida por Derrida, uma vez que a "condição de felicidade" (AUSTIN, [1962] 1990) desse tipo de ato de linguagem, ou seja, a condição para um ato de fala performativo realizar o que enuncia, reside na (re)iteração de determinadas práticas linguísticas e significados sociais convencionais e ritualizados, garantida pela natureza citacional de todo ato de linguagem.

Articulando as perspectivas até aqui discutidas acerca da linguagem como forma de ação e do modo como a performatividade funciona - mediante processos insistentes de deslocamento, repetição e citação de signos em diferentes contextos -, me parece reducionista encarar a violência linguística como direto resultado do caráter injurioso ou depreciativo da acepção semântica de certos itens lexicais de uma língua. Diferentemente disso, acredito que os mecanismos engajados na produção de sentidos violentos na/pela linguagem, em práticas interacionais situadas, dizem respeito aos efeitos performativos de determinados atos de fala que, ao serem enunciados, produzem a evocação/atualização de contextos (pragmática) calcados em significados sociais violentos, interpelando suas vítimas a ocuparem uma posição de vulnerabilidade/precariedade/abjeção/subalternidade no interior desses mesmos contextos instaurados, os quais são produto do engajamento de atores sociais numa atividade específica, no caso, a da violência transfóbica (metapragmática). Enfim, violência linguística diz respeito ao ato de fala que posiciona "o outro especialmente aquele que representa a raça, o gênero, a sexualidade que não se quer habitar - num lugar vulnerável que acaba por insultar, injuriar ou violar [patologizar] a sua condição" (SILVA; ALENCAR, 2013, p. 135, acréscimo meu).

Partindo dessa compreensão, "o contexto deixa de ser concebido como uma série de camadas da estrutura da co-presença intersubjetiva e se torna a produção de sujeitos e a condição de possibilidade para a intersubjetividade" (HANKS, 2008, p. 192). Assim, ser alvo de um ato de fala violento, a exemplo daquele desferido contra as performances corpóreo-discursivas de pessoas trans mediante a entextualização (BAUMAN, BRIGGS, 1990) de discursos patologizantes, destrói "precisamente a orientação contextual e corpórea em que baseamos nossa prática comunicativa" (SILVA; ALENCAR, 2013), sugerindo que ser ferido pela fala é sofrer uma perda de contexto, isto é, não saber onde se está. É justamente nesse sentido que o ato de fala violento coloca o outro num não-lugar. 


\section{3. (CON)TEXTOS EM TRÂNSITO E A (META)PRAGMÁTICA DA VIOLÊNCIA TRANFÓBICA NA LINGUAGEM}

Como consequência da perspectiva de violência linguística (SILVA, 2012; SILVA; ALENCAR, 2013, 2014) em que me detive na seção anterior, me parece possível pensar, também, que ela corresponde a um potencial efeito violento produzido pelo imbricamento entre dinâmicas de ordem pragmática e metapragmática de certos atos de fala, as quais se realizam mediante processos e trânsitos de contextualização em funcionamento na interação situada. Desse modo, ao sustentar que "ser objeto de um enunciado violento implica (...) não saber nem o tempo nem o espaço da violência e estar desorientado em relação a sua própria posição como efeito do ato de fala", Butler (1997, p. 4) faz alusão justamente a essa natureza transtemporal e translocal da circulação dos signos, na qual buscarei me deter nesta seção. Embora estes estejam engajados num texto produzido no aqui/agora interacional, sempre apontam para (indexam) seus contextos de uso anteriores e para a trajetória, a "viagem" trilhada por eles até serem acionados na performance atual, "de tal forma que o texto resultante carrega elementos da história de seu uso consigo" (BAUMAN, BRIGGS, 1990, p. 220).

Para Silverstein (2003), a indexicalidade diz respeito à propriedade que os signos possuem de indicar, sinalizar seus deslocamentos textuais, os quais delineiam as possibilidades interpretativas disponíveis quando situados em contextos localizáveis. Nesse sentido, do ponto de vista da operacionalização dessa ferramenta analítica para a compreensão das dinâmicas indexicais dos recursos semióticos empregados na elaboração dos atos de fala em contexto, e de seus efeitos de sentido, a exemplo do que refletem Gonzalez e Moita Lopes (2018, p. 1113), saliento que "esse construto nos permite identificar como um determinado signo, ao ser empregado em uma dada interação, por conta da repetição de usos, conecta-se com sentidos sociohistoricamente absorvidos".

Assim, se ressalta que os/as participantes que interagem discursivamente em uma atividade social não estão apenas inseridos, submetidos ou influenciados a/por um contexto, mas, também, o estão construindo dinâmica e ativamente no curso da interação, através de dinâmicas constantes de entextualização - processo pelo qual um discurso toma a forma semiótica de um texto, é entextualizado, de modo que uma vez deslocado de seu contexto inicial, se precipita em novos contextos, mediante movimentos infinitos, e significantes, de descontextualização e recontextualização (BAUMAN, BRIGGS, 1990). Tais processos funcionam na relação dialética entre as possibilidades de agência dos sujeitos no uso de diferentes signos compartilhados na construção dos contextos em interações situadas (mediante seus propósitos 
interacionais) e o efeito de conformação, de delimitação exercido pelas coerções macrodimensionais, a exemplo das ideologias, das tipificações das atividades e das relações de poder, quer tenham ciência disso ou não.

Por isso, me parece válido pensar que as referidas negociações/disputas intersubjetivas na sinalização do contexto, em termos do tipo de atividade em curso e do modo como cada um é posicionado e nele se orienta, realizam-se mediante processos de contextualização, os quais são indicados na atividade comunicativa através de pistas de contextualização (GUMPERZ, [1982] 1998) presentes nos atos de fala. Nesse sentido, passam a ser levadas em conta tanto a dimensão interacional imediata quanto uma dimensão mais translocal em que pistas e pressuposições empregadas indicam construtos históricos, socioculturais e ideológicos mais estáveis. Dessa visada, conforme discute Fabrício (2014), numa síntese criativa acerca dos pensamentos de Duranti e Goodwin (1992) e Agha (2007), os contextos não são realidades pré-fabricadas ou pré-discursivas, estando à espera de serem habitadas, mas são produzidos, dialógica e reflexivamente, a partir de processos de contextualização que se realizam nas interações, os quais

funcionam como âncoras, fornecendo um terreno indexical que orienta as pressuposições e expectativas dos interlocutores em relação ao ato interacional, guia seu uso de recursos e estabelece relações entre os signos empregados e os significados socioculturais que eles designam. Além disso, origina relações sociais à medida que categoriza, rotula e valoriza objetos, pessoas e seus ambientes circundantes, tornando-os perceptíveis e iteráveis em muitos encontros (FABRÍCIO, 2014, p. 149, grifo meu).

Nesses termos, a gama de estratégias referenciais e inferenciais das quais os sujeitos lançam mão na elaboração de atos de fala situados está diretamente atrelada às perspectivas de mundo, aos conhecimentos, à experiência e aos repertórios socioculturais partilhados nas práticas linguísticas. Por isso, ao serem acionados, os atos de fala (re)produzem e (re)significam mediante elementos indexicais pragmáticos - contextos mais amplos, os quais sinalizam um tipo de reflexividade acerca do que está sendo feito naquela interação às posições de interpelação produzidas pelos contextos construídos em face de normas sociais, convenções, "identidades" e modelos culturais em jogo - metapragmática (FABRÍCIO, 2014, p. 149).

Nesse sentido, os atos de fala transfóbicos se realizam mediante a produção de contextos que citacionalmente "estabelecem e reafirmam a situação específica em que os enunciados são proferidos" (MEY, 2014, p. 134), ou seja, que atualizam situações sociais/discursos em que a violência de gênero contra pessoas trans é sociohistoricamente praticada, especialmente no que tange às violências dos discursos 
médico-científicos e suas narrativas patologizantes. Uma vez que um enunciador produz esse tipo de contexto, sua fala "tanto se apoia como ativamente cria a situação social" (MEY, 2014, p. 134) da violência, tanto se ancora pragmaticamente em contextos transfóbicos espaço-temporalmente diversos daquele em que ela é proferida, como a realiza, agindo no sentido de (re)produzir tal violência.

Em razão da perspectiva pragmática e socioantropológica da linguagem e das práticas interacionais aqui validada, uma análise (meta)pragmática de atos de fala transfóbicos a partir de pistas de contextualização deve focalizar "os diversos sistemas de signos (linguísticos, não-linguísticos e para-linguísticos) aos quais os usuários recorrem no trabalho referencial e inferencial" (FABRÍCIO, 2014, p. 148), enquanto atividade indexical. Desse modo, a produção dos atos de fala envolve um processo contínuo de seleção de estruturas sintáticas, de registro, de repertório lexical, de construção de imagens, de inclusão de tópicos, entre outros. Apesar disso, conforme Fabrício (2014), não seria acertado afirmar que tais "escolhas" semióticas são completamente racionais ou refletidas, pois, em muitos casos, não resultam de um trabalho intelectual consciente, mas são orientadas pela capacidade aprendida de observar e agir de acordo com contextos interativos em desenvolvimento.

\section{MODOS DE FAZER ESTA PESQUISA: ASPECTOS METODOLÓGICOS E CONTEXTO}

Considerando que os atos de fala que constituem o material de análise deste artigo se realizaram no ciberespaço ${ }^{4}$, parece útil pensar que esse ambiente demanda uma reinvenção dos modos de fazer pesquisa em linguagem, conforme discutem diversos estudos preocupados com as vivências sociais de linguagens online (MOITA LOPES, 2010; BRAGA, 2015; ZACCHI, 2016). Esse fato justifica-se tanto pelas especificidades do funcionamento semiótico nesses espaços, quanto pelos impactos que eles produzem na construção das sociabilidades, em muitos sentidos inimagináveis antes da revolução da web, especialmente das possibilidades geradas/potencializadas na Web $2.0^{5}$ em termos de interconexão e convergência (JENKINS, 2008), reflexividade (GIDDENS, 1991), relativização das fronteiras

4. Segundo Lévy (1999, p. 17), o ciberespaço "é o novo meio de comunicação que surge da interconexão mundial dos computadores. $\mathrm{O}$ termo especifica não apenas a infraestrutura material da comunicação digital, mas também o universo oceânico de informações que ela abriga, assim como os seres humanos que navegam e alimentam esse universo".

5. A Web $2.0 \mathrm{diz}$ respeito à fase atual de desenvolvimento da internet caracterizada, particularmente, pelas possibilidades de interconexão entre usuários/as, participação, colaboração e produção de uma inteligência coletiva. Nesse sentido, configura-se também pela emergência de novos modos de 
entre as esferas pública e privada (RECUERO, 2016) e mobilidade de corpos, textos e posicionamentos identitários "projetados" (GOFFMAN, [1967] 2011).

Assim, conforme argumenta Flike (2008, p. 249) acerca da natureza de pesquisas qualitativas que consideram as transformações propiciadas pela tecnologia e pela constituição de sujeitos interconectados, "a amostragem do material é intencional e a análise do material coletado é bastante flexível". Nesse sentido, ao desenvolver uma pesquisa de inspiração etnográfica virtual, como proposta por Hine (2002), busco, em termos metodológicos, uma prática capaz de produzir inteligibilidades estratégicas sobre performances linguísticas vivenciadas em ambientes virtuais de interação, o campo etnográfico virtual, bem como sobre modos pelos quais mundos semióticos são re/des/construídos, trânsitos textuais em circulação acontecem entre os sujeitos, significados socioculturais são construídos/ compartilhados/disputados em/sobre seus contextos.

Grosso modo, os dados em análise neste trabalho, produzidos numa etnografia virtual realizada entre julho de 2015 e julho de 2016, foram gerados a partir da observação de comentários online postados em duas matérias jornalísticas específicas veiculadas no site de notícias $\mathrm{G}_{1}{ }^{6}$. As matérias em questão referiam-se à intervenção artística da atriz e modelo transexual Viviany Beleboni, que encenou uma crucificação durante a $19^{a}$ edição da Parada do Orgulho LGBT, ocorrida em 06 de junho de 2015, em São Paulo, Brasil. Apesar de suas declarações à mídia afirmando estar "representando as dores e a luta LGBT", a encenação da atriz" gerou, além de episódios de agressão física contra ela, uma grande repercussão negativa nas redes sociais, especialmente entre cristãos mais conservadores, sob o argumento de "profanação, vilipêndio e atentado ao sagrado e à fé", suscitando inclusive notas oficiais de organismos religiosos (a exemplo da Conferência Nacional dos Bispos do Brasil - $\mathrm{CNBB}$ ) e de personalidades ligadas à Igreja Católica e a segmentos protestantes.

Para localização e seleção das matérias as quais teriam sua seção de comentários observada, utilizei o sistema de busca disponível na página do próprio site mediante

pensar, fazer e ser no/o mundo, proporcionados pelas tecnologias da internet, uma modalidade de mindset, conforme pensam Lankshear e Knobel (2007).

6. Os parâmetros que me levaram a escolher o G1 como cenário da pesquisa dizem respeito tanto ao fato de o referido site ter coberto amplamente a polêmica, dedicando várias matérias ao assunto, quanto pela sua popularidade entre diferentes classes sociais e regiões do país, sendo considerado o líder do ranking de acessos entre outros sites do seu gênero, chegando a mais de 49 milhões de acessos por mês.

7. Disponível em: <http://wp.clicrbs.com.br/napontadalingua/2015/06/11/viviany-beleboni-a-transexualque-desfilou-crucificada-desabafa-representei-a-dor-de-quem-morre-por-homofobia/?topo $=5>$. Acesso em: 05 mar. 2017. 
a inserção das palavras-chave TRANSEXUAL + CRUCIFICADA + PARADA GAY. Feito isso, a primeira matéria dentre as selecionadas para observação, em função dos interesses desta pesquisa, tinha data de publicação referente a 10.06.2015, intitulada Cristo "viralizou" - Crucificação na Parada Gay, onda conservadora e ação no STF, de autoria da jornalista Yvone Maggie (186 comentários); já a segunda fora publicada em 11.06.2015, sob o título Bispos divulgam nota contra o uso de imagens religiosas na Parada Gay, assinada por Carolina Dantas (709 comentários), e, por fim, com publicação em 21.06.2016, a matéria Depoimento de transexual 'crucificada' na Parada Gay é adiado em SP, por Will Soares (169 comentários). Dentre o número total de comentários, será analisado um em relação à primeira matéria, e, no tocante à segunda e à terceira, serão analisados três de cada uma.

Apesar do grande número de comentários totalizados nessas três matérias (1.064 comentários), vale salientar que nem todos eles se configuravam como objetos desta pesquisa, uma vez que o foco de investigação aqui validado recai sobre aqueles que eram, marcadamente, compostos de atos de fala transfóbicos. Ou seja, meu interesse analítico está voltado para comentários nos quais seu teor violento se manifestasse tomando como alvo a identidade de gênero, ou, em alguns casos, a presumida orientação sexual de Viviany Beleboni, tomada como gay, a partir dessa política de reconhecimento interseccional.

Visando a compreender o funcionamento (meta)pragmático da violência linguística motivada pela transfobia em comentários online, em termos dos sentidos da patologização atribuídos às vidas trans, conforme discutido nas seções anteriores, proponho como categorias de análise processos de contextualização e pistas linguísticas de contextualização (GUMPERZ, [1982] 1998) concernentes a: a) escolbas lexicais em processos de designação, (re)nomeação e avaliação e b) escolbas semântico-pragmáticas em processos de predicação. Tais categorias serão tomadas em função das trajetórias textuais e dos regimes de entextualização de discursos operados pelos participantes das interações, estabelecendo um nexo entre uma "pragmática da textualidade" e uma "metapragmática da textualidade" (SILVA, 2014), buscando manter ativa a vigilância etnográfica, especialmente no que tange ao imbricamento definitivo entre linguagem e sociedade.

\section{5. "ISSO É ABERRAÇÃO, ALGUM TRAUMA, DISTÚRBIO, PRECISAM DE TRATAMENTO PSIQUIÁTRICO": ATOS DE FALA E TRÂNSITOS VIOLENTOS}

Ao analisar os processos de contextualização operados nos atos de fala que compõem a amostra desta pesquisa, focalizarei o processo de indexação, nas 
práticas de linguagem ali presentes, do que chamo de contextos médico-científicos. Sob esta classificação metodológico-analítica, aqui proposta, residem construtos ideológicos advindos de diversos campos do conhecimento (medicina, biologia, anatomia, fisiologia, genética, dentre outros) que funcionam como saberes-poderes ritualmente evocados no exercício da transfobia na linguagem.

Tais saberes-poderes, nutridos de sua função social normatizadora e reguladora, conferem aos atos de fala transfóbicos a força ilocucionária que lhes garante a sua felicidade, em termos austinianos, mediante entextualizações estratégicas, ou seja, a eficácia em seu empreendimento: violentar pessoas transexuais.

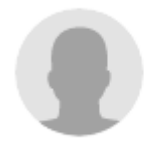

\section{Thiago}

HÁ 2 ANOS

Se o transsexual sofre tanto é culpa dele, pois foi ele que transformou o próprio corpo em uma coisa que esse corpo não é, é ele quem nega a realidade de que ele é homem e sempre será e não serão mil cirurgias e mil hormônios que mudarão isso. É ele que tem que se arrepender da transgressão e mutilação do próprio corpo. Só assim ele vai poder parar de sofrer tanto.

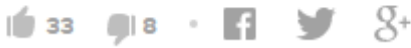

Figura 1. Comentário online de Thiago à matéria "Depoimento de transexual 'crucificada' na Parada Gay é adiado em SP".

Fonte: <http://g1.globo.com/sao-paulo/noticia/2016/06/depoimento-de-transexualcrucificadasobre-parada-gay-e-adiado-em-sp.html $>$. Acessado em: 24 jun. 2017.

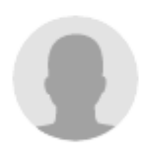

\section{Thales Carvalho}

HÁ 2 ANOS

Primeiro: "atriz" uma ova! ATOR! A não ser que vocês me digam que tela tenha substituído seu cromossomo "Y" pelo "X". Em segundo lugar... Que demora a manifestação da Confederação Nacional dos Bispos Bolivarianos, linha auxiliar do PT, hein? Fosse nos tempos de D. Eugênio Sales, por exemplo, a manifestação de repulsa seria já na noite de domingo.

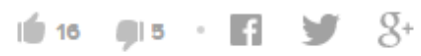

Figura 2. Comentário online de Thales Carvalho à matéria "Depoimento de transexual 'crucificada' na Parada Gay é adiado em SP".

Fonte: <http://g1.globo.com/sao-paulo/noticia/2016/06/depoimento-de-transexualcrucificadasobre-parada-gay-e-adiado-em-sp.html>. Acessado em: 24 jun. 2017. 
Nos comentários registrados pelos comentadores Thiago e Thales Carvalho, a violência transfóbica produz efeitos de sentido a partir de mecanismos de agência em diferentes níveis do ato de fala. Ainda em sua dimensão locucionária, aquela que diz respeito "aos vocábulos com certo sentido e referência mais ou menos definidos" (SILVA, 2012, p. 28), percebo que tanto o comentário na figura 1, pela escolha de formas linguísticas no masculino gramatical (dele; ele) para referir-se à atriz transexual, quanto o na figura 2, pela "correção" à matéria que trata Viviany Beleboni como atriz, no feminino, geram efeitos pragmáticos que denotam uma agência política na linguagem orientada para o não reconhecimento, por parte dos autores dos comentários, da performance de gênero da atriz a quem eles se referem. Nesse sentido, no comentário da figura 2, ao recontextualizar, entre aspas, um índice linguístico de reconhecimento da identificação de gênero de Viviane, empregado pela autora da matéria (Primeiro "atriz" uma ova! ATOR!), o comentador faz uma avaliação negativa sobre tal postura.

Desse modo, as escolhas lexicais em processos de designação, enquanto pistas de contextualização, como que sublinham o juízo desfavorável à legitimidade de sua identificação social, sinalizam metapragmaticamente o não reconhecimento da forma de vida transexual como pertencente a uma matriz binária e cisnormativa de gênero e, por ser este o parâmetro que estabelece as regiões limítrofes do humano, posiciona, contextualmente, as experiências trans numa zona abjeta, por isso relegada a uma condição precária, assim passível de violência.

A fim de potencializar o já referido, no comentário registrado na figura 1, um elemento que pode apontar para o caráter estratégico desse artifício é a pista de contextualização gerada pela escolba de estilo conversacional que se caracteriza pela referência constante ao "objeto", ao "de quem se fala" no comentário, fazendose, assim, necessária a menção reiterada da referência à terceira pessoa, no caso, Viviany Beleboni. Logo, seria forçoso justificar tal repetição como sendo uma estratégia coesiva, uma vez que há um traço estilístico produzido pelo autor com vistas a reiterar essa referência do masculino gramatical, a reiterar a ilegitimidade da identidade de gênero da transexual, a reiterar a violência linguística perpetrada.

Ao avançar na análise, entendo que os empregos gramatical e estilístico, realizados nos níveis locucionários dos proferimentos, passam a suas dimensões mais pragmáticas, mais ligadas aos contextos acionados. Assim, na dimensão ilocucionária do ato de fala proferido, como ilustrado na figura 1, construções como "foi ele quem transformou o próprio corpo em uma coisa que esse corpo não é" apontam para uma leitura essencialista do corpo, ou seja, para uma visão na qual este possui uma essência, um significado imanente a si, independente de aspectos ditos 
exteriores, como a história e a cultura, por exemplo. Nessa perspectiva, a pessoa transexual, por negar essa suposta ontologia do corpo, é interpelada a ocupar uma posição contextual relativa à transgressão.

Mas qual seria esse significado essencialmente inscrito no corpo? Excertos como "é ele que nega a realidade de que é homem e sempre será" sugerem a direção. Assim, a ligação entre corpo e gênero é tomada como unívoca, direta e transparente, argumento esse que funciona como outra estratégia de invalidação da possibilidade de uma identificação diversa daquela supostamente já significada no corpo, de uma identificação não cisgênera.

A essa altura das reflexões aqui encaminhadas, surge a questão sobre de onde vem a força ilocucionária da qual está dotado o ato de fala aqui analisado, como recurso de interdição e, por isso, violência contra as identidades transexuais. Quando é enunciado, no comentário de Thiago, que "não serão mil cirurgias e mil hormônios que mudarão isso", e, no enunciado produzido por Thales Carvalho, que "a não ser que vocês me digam que ela tenha substituído seu cromossomo ' $X$ ' por ' $Y$ ', tal força deixa pistas sobre os processos de contextualização em funcionamento, sobretudo quando considerada a direção para a qual apontam elementos do léxico acionados como "cirurgias", "hormônios" e "cromossomos".

É justamente do contexto médico-científico, e de seus discursos cristalizados acerca do que seja um corpo sexuado, como índice de pertencimento a uma dada categoria humana, atrelada, compulsoriamente, a um "sexo", dito biológico e presentificado no corpo pelo atendimento a uma série de descrições anatômicas e fisiológicas, que advém a força ilocucionária do ato de fala em análise. A referência à suposta inutilidade de procedimentos de saúde relacionados ao processo transexualizador, em face de seu objetivo, "mudar isso" ("a realidade de que é homem e sempre será"), ancora-se novamente na ideia de essência inscrita compulsoriamente no corpo.

Na figura 1, a ordem expressa dirigida à transexual como forma de reverter sua condição e sanar os sofrimentos contra os quais ela protestava na Parada LGBT de São Paulo, em "ele tem de se arrepender da mutilação e da transgressão do próprio corpo", abre espaço para inferências que revelam a natureza normativa e coercitiva da relação linear estabelecida entre corpo e sexo, uma vez que aqueles que a ela não atendem são nomeados como transgressores e moralmente culpabilizáveis.

Nessa mesma direção, no comentário na figura 2, a ironia gerada pela suposição de que a única forma cabível de se designar uma mulher transexual usando palavras femininas, a exemplo de "atriz", seria a alteração de seus dados genéticos - realidade sabidamente impossível nos dias atuais - também aponta para 
os contextos médico-científicos como balizadores da verdade sobre as identidades, reforçando o efeito de estabilidade produzido pelos discursos heteronormativos, conforme Louro (2000, p. 17).

Para além disso, conforme aponta Butler (2000, p. 110), em diálogo com as perspectivas de Foucault (1997, p. 52), o "'sexo' não apenas funciona como uma norma, mas é parte de uma prática regulatória que produz os corpos que governa", em outras palavras, sua força materializa-se como um poder capaz de produzir, de criar, de "demarcar, fazer, circular, diferenciar, os corpos que ela controla". Assim, tal dinâmica de normatização revelada pelos contextos indexados no ato de fala transfóbico em análise é, em última instância, produtora e reguladora de identificações, através de performances discursivas, inclusive de gênero e de sexualidade, posicionadas contextualmente como válidas ou subalternizadas, sendo esta última a posição relegada às pessoas trans.

Assim, a natureza performativa dos atos de fala transfóbicos aqui analisados, cuja força ilocucionária advém das dinâmicas (meta)pragmáticas que acionam e (re) significam contextos nos quais os discursos médico-científicos acionados exercem a violência, como visto nos comentários nas figuras 1 e 2, revela o modo como a linguagem em uso funciona no sentido de materializar semioticamente, normatizar e policiar as diferenças em termos de sexo e de gênero. Nesse sentido, conforme propõe Butler (2000, p. 111) que

\begin{abstract}
a performatividade deve ser compreendida não como um "ato" singular ou deliberado, mas, ao invés disso, como a prática reiterativa e citacional pela qual o discurso produz os efeitos que ele nomeia. [...] As normas regulatórias do "sexo" trabalham de uma forma performativa para constituir a materialidade dos corpos e, mais especificamente, para materializar o sexo do corpo, para materializar a diferença sexual a serviço da consolidação do imperativo heterossexual.
\end{abstract}

Ancorados nessa visada, a materialização do sexo no corpo pode ser entendida como um efeito pragmático, performativo, uma vez que os atos de fala produzem aquilo que nomeiam, são uma forma de ação que fabrica "verdades" sobre os corpos, os sexos e os gêneros e, a partir delas, produzem subjetividades. Nesse sentido, nos comentários de Patrick Moraes e Roberto, nas figuras 3 e 4 que seguem, fica saliente uma tentativa de gerar efeitos de estabilidade na diferenciação entre os sexos como estratégia para negar o caráter performativo (e falso, em termos essencialistas) do corpo, do sexo e do gênero, a menção a aspectos corporais que, segundo a estabilidade imaginada, amplamente validada nos saberes binários e dimórficos dos discursos médico-científicos, seriam critérios válidos para distinguir homens de mulheres. 
Não obstante seja possível considerar que em ambos os atos de fala há processos de contextualização que acionam indexicalmente outros contextos (como o religioso e o da abjeção), bem como entextualizam discursos de outras ordens, continuarei focalizando aqueles relativos aos médico-científicos, intento das análises empreendidas neste trabalho.

\section{Patrick Moraes}

HÁ 2 ANOS

Esse homem, sem o saco, não podia brincar com com isso. Na marcha pra jesus alguma bandeira LGBT foi queimada? Havia algum cartaz falando contra eles? Houve alguma manifestação contra essa gente promiscua?

Figura 3. Comentário online de Patrick Moraes à matéria "Cristo viralizou - crucificação na Parada Gay, onda conservadora e ação no STF".

Fonte: <http://g1.globo.com/pop-arte/blog/yvonne-maggie/post/cristo-viralizoucrucificacaoglbt-onda-conservadora-e-acao-no-stf.html>. Acesso em: 24 jun. 2017.

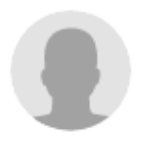

\section{Roberto}

HÁ 8 MESES

\section{Coisas: 1)Modelo, atriz ? Mudou de nome a profissão de prostituta? 2)Está com mais pelo no braço que eu...rs}

Figura 4. Comentário online de Roberto à matéria "Bispos divulgam nota contra o uso de imagens religiosas na Parada Gay".

Fonte: <http://g1.globo.com/sao-paulo/noticia/2015/06/bispos-divulgam-nota-contrauso-deimagens-religiosas-na-parada-gay.html>. Acesso em 24 jun. 2017.

Como representado na figura 3, o modo como o comentador produz pistas de contextualização relativas às escolhas lexicais em funcionamento no processo de nomeação, as quais categorizam a experiência de uma mulher trans ("esse bomem, sem saco"), realiza violência linguística de motivação transfóbica por meio do reestabelecimento de contextos ritualizados que interditam sua identidade de gênero a partir de justificativas biologizantes. A referência a uma suposta ausência de parte da genitália masculina, os testículos, autoriza inferências do tipo "você não é uma mulher, é apenas um homem sem saco". Inferências do tipo produzem efeitos de sentido como os dos comentários 3 e 4, ou seja, a suposta "mutilação" da estrutura 
corporal masculina, incidindo sobre uma região que é metaforicamente o índice dessa masculinidade, não altera aquilo que, de fato, ela é, "um homem ainda que sem saco".

No comentário na figura 3, a suposta eliminação de um caractere iconicamente associado ao masculino não foi capaz de evitar a transexual de ser nomeada/designada e lida socialmente como um homem, segundo uma matriz sexogenérica cisheteronormativa, reafirmando-se, assim, sua suposta realidade essencial, ontológica, verdadeira, a despeito das intervenções ou das "distorções" que a dimensão material do corpo possa comportar. Já no comentário reproduzido na figura 4, a lógica se inverte, mas operando com os mesmos efeitos pragmáticos. Nele, é justamente a presença de um caractere reconhecido culturalmente como sendo masculino - a presença de pelos no corpo - o elemento que deslegitima a performance de gênero transexual e a produz como uma identidade subalterna e ininteligível socialmente.

Desse modo, aqui se combinam, e funcionam, na produção da violência transfóbica na linguagem, a verdade tácita em que se configuram determinadas narrativas médico-científicas acerca do corpo e do sexo como dados "biológicos", cristalizadas no imaginário social e ritualizadas nas mais diversas práticas, e uma certa perspectiva metafísica da identidade corporificada, que atribui, automaticamente, significados sociais às estruturas anatomofisiológicas do corpo, parte fulcral do modelo biomédico de identidade (CAMARGOJR., 2005). Assim, ambos os saberespoderes são tomados como plenamente desprovidos de conotações ideológicas e/ ou políticas, marcadas social e historicamente, assumindo-se, assim, uma espécie de limbo social no qual as identificações de sexo e gênero se materializariam.

\section{Cláudio Oliveira \\ HÁSANOS \\ Da mesma forma, se religiosos fizerem marcha para Jesus, colocarem um gay pendurado numa forca seria um absurdo. Não devemos misturar as coisas e muito menos patrocinar ou fomentar a intolerância. Foi irresponsabilidade deste homem, em casca de mulher, fazer o que fez. Não é porque tem peito de silicone, e cabelos femininos, que virou mulher. É homem e tem que respeitar para ser respeitado.}

Figura 5. Comentário online de Cláudio Oliveira à matéria "Depoimento de transexual 'crucificada' na Parada Gay é adiado em SP".

Fonte:<http://g1.globo.com/sao-paulo/noticia/2016/06/depoimento-de-transexualcrucificadasobre-parada-gay-e-adiado-em-sp.html $>$. Acesso em: 24 jun. 2017.

Ainda nesse fluxo metapragmático, os recursos semióticos de natureza linguística indexados no comentário de Cláudio Oliveira, na figura 5, ratificam uma regularidade relativa nos regimes de entextualização de discursos médicos, os quais significam 
as experiências trans, por um lado, como falsas, do ponto de vista de um modelo essencialista e ontológico de identidade articulado em seu bojo, ou como resultados de distorções/desvios de um destino identitário fixo e estável ditado pelos manuais médicos. É em direções interpretativas como essas que processos de contextualização operados por predicações que entextualizam o discurso médico-científico da ontologia biológica são significados como em "homem em casca de mulher".

Ademais, é nessa segurança ontológica (BENTO; PELÚCIO, 2012) produzida por esses discursos que legitimam a máxima tácita de que cada sujeito é o resultado da determinação de seus hormônios que se ancoram pistas de contextualização como "não é porque tem peito de silicone, e cabelos femininos, que virou mulher". Tal entextualização sinaliza a deslegitimação da eficácia das tecnologias de gênero (LAURETIS, 1987) empregadas por pessoas trans a fim de se construírem em corpo, alma e silicone. Nessa operação, são acionados indexicalmente sentidos que escamoteiam a natureza performativa, ou seja, produzida e, em algum sentido, "artificial", de toda estilização de gênero, movendo essa marca de "falsidade" exclusivamente para pessoas trans, numa tentativa de delimitar as fronteiras entre a esfera do verdadeiro/natural e do falso/artificial, do que fazem, segundo a posição interacional projetada por Cláudio, "os homens em casca de mulher".

Paradoxalmente, emergem também sentidos que descolam as performances de gênero dos corpos sexuados e designados compulsoriamente, em decorrência de uma leitura essencialista de caracteres corporais. Ao enunciar que um homem, na leitura cisheteronormativa que faz de Viviane Beleboni, pode ter "cabelos femininos" ou ainda que "ser" mulher é um devir, em expressões como "virar mulher", os signos que instauram a metapragmática do não reconhecimento de vidas trans ao serem repetidos, recontextualizados no comentário de Cláudio, iteram esse significado, alterando-o, ainda que tal possibilidade não seja fruto de uma escolha racional dele.

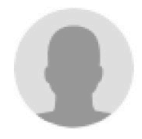

\section{Catolico Reumatico}

HÁ BANOS

aonde ja se viu ,mulher com mulher ou homem com homem, isso é aberraçao e disturbio ,algum trauma ,precisam de tratamento psiquiatrico .

Figura 6. - Comentário online de Catolico Reumatico à matéria "Bispos divulgam nota contra o uso de imagens religiosas na Parada Gay".

Fonte: <http://g1.globo.com/sao-paulo/noticia/2015/06/bispos-divulgam-nota-contrauso-deimagens-religiosas-na-parada-gay.html>. Acessado em 24 jun. 2017. 


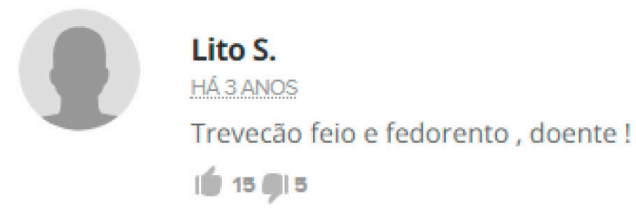

Figura 7. Comentário online de Lito S. à matéria "Bispos divulgam nota contra o uso de imagens religiosas na Parada Gay.

Fonte: <http://g1.globo.com/sao-paulo/noticia/2015/06/bispos-divulgam-nota-contrauso-deimagens-religiosas-na-parada-gay.html>. Acessado em 24 jun. 2017.

No enunciado produzido pelo comentador autointitulado "Catolico Reumatico", na figura 7, são acionadas pistas de contextualização indexicalmente estabelecidas por escolbas semântico-pragmáticas em processos de predicação, a exemplo de "isso é aberração e distúrbio, algum trauma" e "precisa de tratamento psiquiátrico". Nesse sentido, são atualizados contextos nos quais as existências trans são significadas no lugar da doença, do transtorno de gênero, cujos critérios para o seu diagnóstico "são os deslocamentos de gênero em relação ao sexo biológico, pois o gênero normal só existe quando referenciado a um sexo genital que o estabiliza" (BENTO; PELÚCIO, 2012, p. 572).

Nesse comentário, são entextualizados discursos médico-científicos, especialmente aqueles advindos das ciências do comportamento humano, da psiquiatria, da psicologia e da psicanálise, os quais produzem uma orientação contextual que interpela pessoas trans a ocuparem a posição de traumatizadas, acometidas por uma enfermidade, vitimadas por um sofrimento psíquico decorrente de sua situação de inconformidade (disforia de gênero) entre "corpo" e "alma". Longe de serem ponderações empáticas acerca dessas pessoas e de suas condições de existência, essas dinâmicas contextuais atualizam uma narrativa da patologização da transexualidade calcada no escamoteamento do fato de que as ciências médicas não possuem nenhuma evidência técnica, de caráter biológico ou baseada em testes, que possa justificar ou explicar a inscrição dos trânsitos de gênero no escopo de sua nosologia.

Assim, a fim de poderem exercer sua tutela biopolítica sobre os corpos trans (mediante prescrição de drogas farmacêuticas, procedimentos cirúrgicos, emissão de laudos, dentre outros), táticas discursivas complexas transmutam percepções hegemônicas acerca das feminilidades e masculinidades, situadas num marco histórico e cultural específico (FOUCAULT, [1969] 2009), em verdades 
absolutas e inquestionáveis, legitimadas pelo poder do Estado e da mídia, especialmente sob o argumento de sua cientificidade e isenção ideológica.

No comentário elaborado pelo participante Lito S., se pode notar os efeitos de violência linguística produzidos pelos sentidos de abjeção indexados em processos de nomeação como em "Traveção" e em processos de avaliação como em "feio" e "fedorento", os quais evocam os marcos estéticos que balizam as sensibilidades transfóbicas e suas capacidades limitadas de leitura da diferença desde o modelo reducionista de beleza/normalidade cisheterossexual. Nesse sentido, há que se pensar no "importante papel desempenhado pelos termos escolhidos a fim de designar os indivíduos, acontecimentos, lugares, etc. na formação da opinião pública a respeito daqueles entes" (RAJAGOPALAN, 2004, p. 85).

Sendo assim, fica autorizado considerar que o discurso clínico se configura "enquanto prática, que instaura [...] um sistema de relações que não é 'realmente' dado nem constituído a priori" (FOUCAULT, [1969] 2009, p. 60). Nesse âmbito, as lógicas de normalidade-anormalidade, saúde-doença, se dão no sentido da produção de uma epistemologia da vida e dos corpos que são tomados como realidades dadas, ontológicas e pré-significadas.

Nessa perspectiva foucaultiana, "a medicina e o médico são, portanto, o primeiro objeto da normalização. Antes de aplicar a noção de normal ao doente, se começa por aplicá-la ao médico" (FOUCAULT, 1986, p. 83). Pensando a normalidade como um conceito a ser aplicado sobre corpos e subjetividades e não como uma "realidade", pré-existente à sua conceptualização, a ser averiguada mediante o (não) atendimento de uma série de condicionalidades e descrições previstas em manuais de medicina, vejo que os sentidos atravessados pelo gênero, tais como "mulher normal", "mulher de verdade", "sexo biológico", "função reprodutiva do sexo", "ato sexual normal", "sexualidade natural", "função dos genitais", "transexual verdadeiro", dentre outros, atuam, segundo um posicionamento ideológico e sociohistoricamente situado, na produção de verdades excludentes que retroalimentam o ideário da heterossexualidade compulsória e da cisnormatividade.

Compreendendo, assim, a dinâmica do funcionamento discursivo desses saberes-poderes, fica melhor entender como sua perspectiva biologizante, constituída a partir da necessidade de categorizar a anormalidade como condição para se pensar, então, a normalidade, atua na base de muitos discursos entextualizados nos atos de fala engajados em interações situadas com vistas a produzir violência linguística contra pessoas trans. 


\section{CONSIDERAÇÕES FINAIS}

Ao cabo da trajetória teórico-analítica empreendida neste artigo, acredito ter sido possível produzir uma inteligibilidade contingente, pois situada por minhas trajetórias pessoais enquanto sujeito social e por meus interesses nesta pesquisa, em torno do funcionamento (meta)pragmático da violência linguística produzida por atos de fala transfóbicos os quais recorrem às narrativas médico-científicas no sentido de patologizar experiências transexuais. Desse modo, é possível entrever como práticas de linguagem, a exemplo das aqui discutidas, mediante seu caráter performativo, podem contribuir para a compreensão da base semiótica dos entraves institucionais para a promoção da cidadania integral e efetiva de pessoas trans. Ademais, para a necessária problematização de questões relativas à responsabilidade pelos atos de fala violentos e da constituição de uma esfera ética do dizer que, ao invés de escamotear, desnaturalize políticas de significação que fazem transbordar sobre tais formas de vida a força disciplinar da matriz cisnormativa, relegando corpos, vidas e trajetórias trans ao espaço da doença e da medicalização.

Em sentido amplo, aventurando-me numa reflexão metateórica e metametodológica da pesquisa aqui relatada, sustento que a desestabilização de saberes-poderes que operam dentro de lógicas binárias da normalidade/anormalidade próprias do racionalismo modernista da ciência ocidental - as mesmas que atribuem significados sociais aos corpos, suas anatomias e possibilidades identitárias - é de fundamental importância para a relativização de discursos normativos centrados e, consequentemente, para a produção de subjetividades outras desde sua dimensão somática. Nesse sentido, penso na necessidade estratégica de adensamento e proliferação de pesquisas em linguagem que focalizem as relações entre interações multissemióticas situadas e os mais diversos marcadores sociais da diferença e suas interseccionalidades, como agência política em favor da contaminação com a vida, ensejando trabalhos mais cartográficos que cartesianos, inspirados na "arte de construir um mapa sempre inacabado, aberto, composto de diferentes linhas, conectável, desmontável, reversível, susceptível de receber modificações constantemente" (DELEUZE; GUATTARI, 1996, p. 21).

\section{$\overline{\text { REFERÊNCIAS }}$}

ALENCAR, C. N. Searle interpretando Austin: a retórica do "medo da morte" nos estudos da linguagem. 2005. 275f. Tese de Doutorado. Instituto de Estudos da Linguagem. Unicamp, Campinas, 2005. 
AUSTIN, John Langshaw. (1962). Quando dizer é fazer. Tradução de Danilo Marcondes de Souza Filho. Porto Alegre: Artes Médicas, 1990.

BAKHTIN, M. (1979). Os gêneros do discurso (1952-1953). In: Estética da criação verbal. Tradução de Maria Ermantina Galvão Gomes e Pereira. São Paulo: Martins Fontes, 2002, pp. 277-326.

BAUMAN, R.; BRIGGS, C. (1990). Poetics and performance as critical perspectives on language and social life. In: COUPLAND, N.; JAWORSKI, A. (Orgs.). The new sociolinguistics reader. New York: Palgrave Macmillian, 2010, pp. 185-217.

BENTO, B. (2014). O que pode uma teoria? Estudos transviados e a despatologização das identidades trans. Florestan, ano 1, n. 2, pp. 46-66.

BENTO, B.; PELÚCIO, L. (2012). Despatologização do gênero: a politização das identidades abjetas. Rev. Estud. Fem., 20, 2, pp. 559-568.

BLOMMAERT, J. (2005). Discourse. A Critical Introduction. Cambridge: Cambridge University Press.

BLOMMAERT, J. (2010). The sociolinguistics of globalization. Cambridge: Cambridge University Press.

BORBA, R. (2016). O (des) aprendizado de si: transexualidades, interação e cuidado em saúde. Rio de Janeiro: Editora Fiocruz.

BRAGA, D. B. (2015). Tecnologias digitais da informação e da comunicação e participação social. São Paulo: Cortez, pp. 33-67.

BUTLER, J. (1990). Problemas de gênero: feminismo e subversão da identidade. Tradução de Renato Aguiar. Rio de Janeiro: Civilização Brasileira, 2017.

BUTLER, J. (1996). Corpos que pesam: sobre os limites discursivos do "sexo". Tradução de Thomas Tadeu da Silva. In: LOURO, Guacira Lopes. O corpo educado: pedagogias da sexualidade. 2 ed. Belo Horizonte: Autêntica, 2000.

BUTLER, J. (1997). Excitable speech: a politics of the performative. London: Routledge.

BUTLER, J. (2009). Quadros de guerra: quando a vida é passível de luto. Tradução de Sérgio Lamarão e Arnaldo Marques da Cunha. Rio de Janeiro: Civilização Brasileira, 2017. 
CAMARGO JR., K. (2005). A biomedicina. Physis: Rev. Saúde Coletiva, Rio de Janeiro, 15 (Suplemento), pp. 177-201.

DELEUZE, G.; GUATTARI, F. (1996). Mil platôs: do capitalismo à esquizofrenia. v. 1. Tradução de Aurélio Guerra Neto e Célia Pinto Costa. Rio de Janeiro: Editora 34.

DERRIDA, J. (1988). Assinatura, acontecimento, contexto. In: DERRIDA, J. Margens da filosofia. Tradução de Joaquim Torres Costa, Antônio M. Magalhães. Campinas: Papirus, 1991b, pp. 349-373.

DERRIDA, J. (1988). Limited Inc. Tradução de Constança Marcondes Cesar. Campinas: Papirus, 1991a.

DURANTI, A.; GOODWIN, C. (Eds.) Retbinking context. Language as an interactive phenomenon. Studies in the social and cultural foundations of language, n. 11. Cambridge: Cambridge University Press, 1992.

FABRÍCIO, B. F. (2014). Transcontextos educacionais: gêneros, sexualidades e trajetórias de socialização na escola. In: SILVA, D.; ALENCAR, C. N.; FERREIRA, D. M. M. (Orgs). Nova Pragmática - Modos de Fazer. São Paulo: Cortez, pp. 145-189.

FLIKE, U. (2008). Introdução à pesquisa qualitativa. Tradução de Joice Elias Costa. 3. ed. Porto Alegre: Artmed.

FOUCAULT, M. (1969). A Arqueologia do Saber. Tradução de Luís Felipe Baeta Neves. Rio de Janeiro: Forense Universitária, 2009.

FOUCAUlT, M. (1970). A ordem do discurso. Tradução de Laura Fraga de Almeida Sampaio. São Paulo: Edições Loyola.

FOUCAULT, M. (1976). História da sexualidade I: A vontade de saber. Tradução de Maria Thereza da Costa Albuquerque e J. A. Guilhon Albuquerque. Rio de Janeiro: Graal, 1988.

FOUCAULT, M. (1980). "Two lectures". In: GORDON, Colin (Org.). Power/Knowledge: selected writings, interviews \& other writings - 1972-1977. New York: Pantheon Books.

FOUCAULT, M. (1986). Microfísica do Poder. Org. e Tradução de Renato Machado. Rio de Janeiro: Ed. Graal. 
GIDDENS, A. (1991). As consequências da modernidade. Tradução de Raul Fiker. São Paulo: Unesp.

GIDDENS, A. (2002). Modernidade e identidade. Tradução de Plínio Dentzien. Rio de Janeiro: Zahar.

GOFFMAN, E. (1967). Rituais de interação. Ensaios sobre o comportamento face a face. Tradução de Fábio Ribeiro da Silva. Petrópolis: Editora Vozes, 2011.

GONZALEZ, C.; MOITA LOPES, L. P. (2018). Reflexividade metapragmática sobre o cinema de Almodóvar numa interação online: indexicalidade, escalas e entextualização. Trab. Ling. Aplic., Campinas, n. (57.2). pp. 1102-1136.

GOODWIN, C.; GOODWIN, M. H. (1992). Assessments and the construction of context. In: DURANTI, A.; GOODWIN, C. (Eds.). Retbinking context. Language as an interactive phenomenon. Studies in the social and cultural foundations of language n. 11. Cambridge: Cambridge University Press. pp. 147-219.

GUIMARÃES, T. F.; MOITA LOPES, L. P. (2016). Entextualizações estratégicas: performances sensualizadas de raça em práticas discursivas na Web. 2.0. Linguagem em Discurso - LemD, Tubarão, SC, v. 16, n. 2, pp. 289-307.

GUMPERZ, J. (1982). Convenções de contextualização. In: RIBEIRO, B. T; GARCEZ, P. M. (Orgs.). Sociolinguística Interacional. Porto Alegre: Age, 1998.

GUMPERZ, J. (2002). Entrevista com John Gumperz. In: PEREIRA, M. G. D.; GARCEZ, P. M. (Orgs. e Eds.). Palavra. v. 8. Rio de Janeiro: PUC-RJ.

HANKS, W. F. (2008). Língua como prática social: das relações entre língua, cultura e sociedade a partir de Bourdieu e Bakhtin. São Paulo: Cortez, 2008.

HINE, C. (2002). Virtual Ethnography. London: Sage Publications.

JENKINS, E. (2008). Cultura de convergência. Tradução de Susana Alexandria. São Paulo: Editora Alexandria.

LANKSHEAR, C.; KNOBEL, M. (2007). Sampling the new in the new literacies. In: KNOBEL, M.; LANKSHEAR, C. (Orgs.). A new literacies sampler. Nova York: Peter Lang.

LAURETIS, T. (1987). Technologies of gender. Nova York: Routledge.

LÉVY, P. Cibercultura. Tradução de Carlos Irineu da Costa. São Paulo: Editora 34, 1999. 
LOURO, G. L. (2000). Pedagogias da sexualidade. In: LOURO, G. (Org.). O corpo educado: pedagogias da sexualidade. 2. ed. Belo Horizonte: Autêntica, pp. 7-34.

MBEMBE, A. (2018). Necropolítica. São Paulo, n-1 edições.

MEY, J. (2014). Sequencialidade, contexto e forma linguística. Tradução de Ive Brunelli. In: SILVA, D. N.; FERREIRA, D. M. N.; ALENCAR, C. F. Nova Pragmática: modos de fazer. São Paulo: Cortez, 2014, pp. 129-144.

MISKOLCI, R. (2016). Teoria Queer: um aprendizado pela diferença. 3. ed. Belo Horizonte: Autêntica Editora.

MOITA LOPES, L. P. (2010). Os novos letramentos digitais como lugares de construção de ativismo político sobre sexualidade e gênero. Trab. Linguist. Apl., v. 49 , n. 2, pp. $393-417$.

OTTONI, P. (2002). John Langshaw Austin e a visão performativa da linguagem. D.E.L.T.A., v. 18, n. 1, pp. 117-183.

PINTO, J. P. (2007). Conexões teóricas entre performatividade, corpo e identidade. D.E.L.T.A, 23:1, pp. 1-26.

RAJAGOPALAN, K. (2010). Nova pragmática: fases e feições de um fazer. São Paulo: Parábola Editorial.

RAJAGOPALAN, K. (1996). O Austin do qual a linguística não tomou conhecimento e a linguística com a qual Austin sonhou. D. E. L. T. A., v. 30, p. 105-115, jan./jun.

RAMPTON, B. (2006) Continuidade e mudança nas visões de sociedade em Linguística Aplicada. In: MOITA LOPES, Luiz Paulo da (Org.). Por uma Linguística Aplicada Indisciplinar. São Paulo: Parábola Editorial, pp. 108-128.

RECUERO, R. (2016). Discurso mediado por computador nas redes sociais. In: ARAÚJO, J.; LEFFA, W. (Orgs.) Redes sociais e ensino de línguas: o que temos de aprender. São Paulo: Parábola Editorial.

SILVA, D. (2014). O texto entre a entextualização e a etnografia: um programa jornalístico sobre belezas subalternas e suas múltiplas recontextualizações. Linguagem em (Dis)curso - LemD, Tubarão, SC, v. 14, n. 1, pp. 67-84.

SILVA, D. N. (2012). Pragmática da violência: o nordeste brasileiro na mídia. Rio de Janeiro: 7 Letras. 
SILVA, D. N.; ALENCAR, C. N. (2013). A propósito da violência na linguagem. Cadernos de Estudos Linguísticos, v. 55, n. 2, pp. 129-146.

SILVA, D. N.; ALENCAR, C. N. (2014). Violência e significação. In: SILVA, D.; ALENCAR, C. N.; FERREIRA, D. M. M. (Orgs.). Nova Pragmática - Modos de Fazer. São Paulo: Cortez, pp. 259-886.

SILVA, D. N.; VERAS, V. (2016). Da teoria dos atos de fala à nova pragmática: os legados de John L. Austin e Kanavillil Rajagopalan. D. E. L. T. A, n. 32.3, pp. 5-19.

SILVA, D. C. P. (2017). Atos de fala transfóbicos no ciberespaço: uma análise pragmática da violência linguística. 2017. 200f. Dissertação (Mestrado em Letras) - Programa de Pós-Graduação em Letras, Universidade Federal de Sergipe, São Cristóvão, 2017.

SILVA, D. C. P. (2019). Emancipação das mulheres no discurso feminista online: dimensões textuais de uma luta hegemônica. Linguagem \& Ensino, v. 22, n. 1, p. 239-262.

SILVESTREIN, M. (2003). Indexical order and dialetics of sociolinguistics life. Lenguage \& Comunication, v. 23, n. 3-4, pp. 193-229.

LEITE, A.; SANTOS, C. (2016). Cartografias Trans: mapas sobre a apropriação médica das transexualidades. Clínica \& Cultura, v. 5, n. 1, pp. 50-64, jan-jun.

SOUSA, G. M. (2011). Pistas de contextualização em negociações de contexto: uma análise linguística no contexto interacional fórum de discussão. Vertentes \& Interfaces II: Estudos Linguísticos e Aplicados, v. 3 n. 2, jan./jun., 2011, pp. 199-209.

VERGUEIRO, V. S. (2015). Por inflexões decoloniais de corpos e identidades de gênero inconformes: uma análise autoetnográfica da cisgeneridade como normatividade. Dissertação de Mestrado em Cultura e Sociedade, Programa Multidisciplinar de Pós-Graduação em Cultura e Sociedade, UFBA, Salvador.

ZACCHI, J. V. (2016). A enxada e a caneta: linguagem e cultura na construção da identidade do sem-terra. São Paulo: Humanitas: FAPESP.

Recebido: $1 / 12 / 2018$

Aceito: 20/07/2019

Publicado: 7/08/2019 